\title{
RARE PRESENTATION OF OLFACTORY NEUROBLASTOMA: CASE REPORT
}

Ravi Kumar Raju Mudunuri'1, Malladi Subramanya Sarma ${ }^{2}$

\section{HOW TO CITE THIS ARTICLE:}

Ravi Kumar Raju Mudunuri, Malladi Subramanya Sarma. "Rare Presentation of Olfactory Neuroblastoma: Case Report". Journal of Evolution of Medical and Dental Sciences 2014; Vol. 3, Issue 18, May 05; Page: 5029-5031, DOI: $10.14260 /$ jemds/2014/2549

ABSTRACT: Olfactory Neuroblastoma (Esthesio neuroblastoma) is a rare neuroectodermal tumour. Presentation includes nasal obstruction, recurrent epistaxis, Hyposmia, anosmia, rhinorrhoea. Treatment includes primary excision and/or radiotherapy, chemotherapy. Here we report an unusual case with presentation of mass in nasopharynx with no specific symptoms and incidental cervical nodes.

KEYWORDS: esthesioneuroblastoma, neurectodermal tumor, Immunohistochemistry, hyposmia.

CASE REPORT: A 35 yr old woman presented to ENT outpatient clinic with multiple neck swellings bilaterally. Minimal discomfort in nasal breathing reported. No other associated symptoms either in neck or nose. Examination revealed multiple non tender firm cervical nodes in level II and III, biggest about $2 \times 2 \mathrm{cms}$. Thorough examination with nasoendoscopy revealed a mucosa covered swelling in the nasopharynx arising from the roof going downwards. MRIFig.2 showed mass confined to nasopharynx, anterosuperiorly extending till choanae. Initial FNAC and later excision biopsy of the neck nodes reported as non specific inflammatory changes. Biopsy from the mass in nasopharynx revealed rosettes ${ }^{\mathrm{Fig} .1}$ in the field, reported as possible olfactory neuroblastoma. ImmunohistochemistryFig.1 confirmed the diagnosis with the pattern consistent with olfactory neuroblastoma. After clinicopathological review, (owing to non specific nodes) it was decided to send the patient for chemotherapy for which patient responded well with regression of nasopharyngeal mass. Long term follow-up is planned as part of further management.

DISCUSSION: Esthesioneuroblastoma (olfactory neuroblastoma) is a rare neuroectodermal tumour, 1 which is challenging for multidisciplinary management, as so far there is no known accepted standard therapy. ${ }^{2}$ It is thought to arise from the olfactory epithelium.

They are highly malignant and metastasize widely. Seen with bimodal peaks in 2 and $6^{\text {th }}$ decades ${ }^{1}$. Presentation can be with nasal obstruction, headaches, sinus problems, facial pain, facial swelling, hyposmia, anosmia, diplopia, haemorrhage or neurological deterioration etc. Examination reveals a mass either in nasal cavity, skull base extending to paranasal sinuses or intracranially. It can also metastasise to cervical lymph nodes.

Microscopically, the tumour is composed of small round cells (slightly larger than lymphocytes) and neurofibrillar matrix, often forming rosettes. Electron microscopy if available shows neural processes and membrane bound secretory granules.

Immunohistochemistry 3 shows neuron specific enolase, synaptophysin, S-100 protein positive sustentacular cells, keratin negativity, neuroendocrine marker positivity. ${ }^{4}$ Most of them show $11 ; 22$ translocation and some reveal trisomy 8.

Prognosis is variable. Other differential diagnoses with similar histological appearances but different immunohistochemistry features include Rhabdomyosarcoma, Malignant lymphoma. ${ }^{5}$ 
Olfactory neuroblastomas (or esthesioneuroblastomas) are most frequently staged using a system proposed by Kadish et al ${ }^{6}$ in 1976.

- group A : tumour is limited to the nasal cavity

- group B : tumour is limited to the nasal cavity and paranasal sinuses

- group C : tumour extends beyond the nasal cavity and paranasal sinuses

$\circ$ base of skull

○ intracranial compartment

o orbit

- distant metastatic disease

An additional group D has been proposed by Chao et al ${ }^{7}$ in 2001.

- group D : cervical nodal metastases

Treatment modalities are variable as is the condition. It might include surgery, or chemotherapy (with cisplatin,8,9 etoposide 9 or cyclophosphamide, vincristine with or without Doxorubicin) or radiotherapy or multimodal approach ${ }^{2}$ which is used in majority of cases. Outcome depends on the stage. Recurrence is common. Palliative management done in cases of advanced stages and recurrence.

Here we present an unusual presentation of a case with histologically negative cervical nodes and nasal obstruction.

\section{REFERENCES:}

1. Sampath P, Park MC, Huang D, Deville C, Cortez S, Chougule P. Esthesioneuroblastoma (Olfactory Neuroblastoma) with Hemorrhage: An Unusual Presentation. Skull Base. 2006 Aug; 16(3):169-73.

2. Koch M, Constantinidis J, Dimmler A, Strauss C, Iro H. Long-term experiences in the therapy of esthesioneuroblastoma. Laryngorhinootologie. Oct 2006; 85(10):723-30.

3. Faragalla H, Weinreb I. Olfactory neuroblastoma: a review and update. Adv Anat Pathol 2009. Sep; 16(5):322-31.

4. Zhang M, Zhou L, Wang DH, Huang WT, Wang SY. Diagnosis and management of esthesioneuroblastoma. ORL J Otorhinolaryngol Relat Spec 2010, 72(2):113-8.

5. Liu HG, Zhang SZ, He CY. Study on pathological features and diagnosis, differential diagnosis of olfactory neuroblastoma. Zhonghua Bing Li Xue Za Zhi, 2003 Oct;32(5):432-6.

6. Kadish S, Goodman M, Wang C C. Olfactory neuroblastoma- A clinical analysis of 17 cases. Cancer 1976, 37 (3) : 1571-6.

7. Chao KS, Kaplan C, Simpson JR et al. Esthesioneuroblastoma : the impact of treatment modality. Head Neck 2001, 34 (9): 749-57.

8. McElroy EA Jr, Buckner JC, Lewis JE. Chemotherapy for advanced esthesioneuroblastoma: the Mayo Clinic experience. Neurosurgery. 1998 May;42(5):1023-7.

9. Porter AB, Bernold DM et al. Retrospective review of adjuvant chemotherapy for esthesioneuroblastoma. Neurooncol. 2008 Nov;90(2):201-4. 


\section{CASE REPORT}
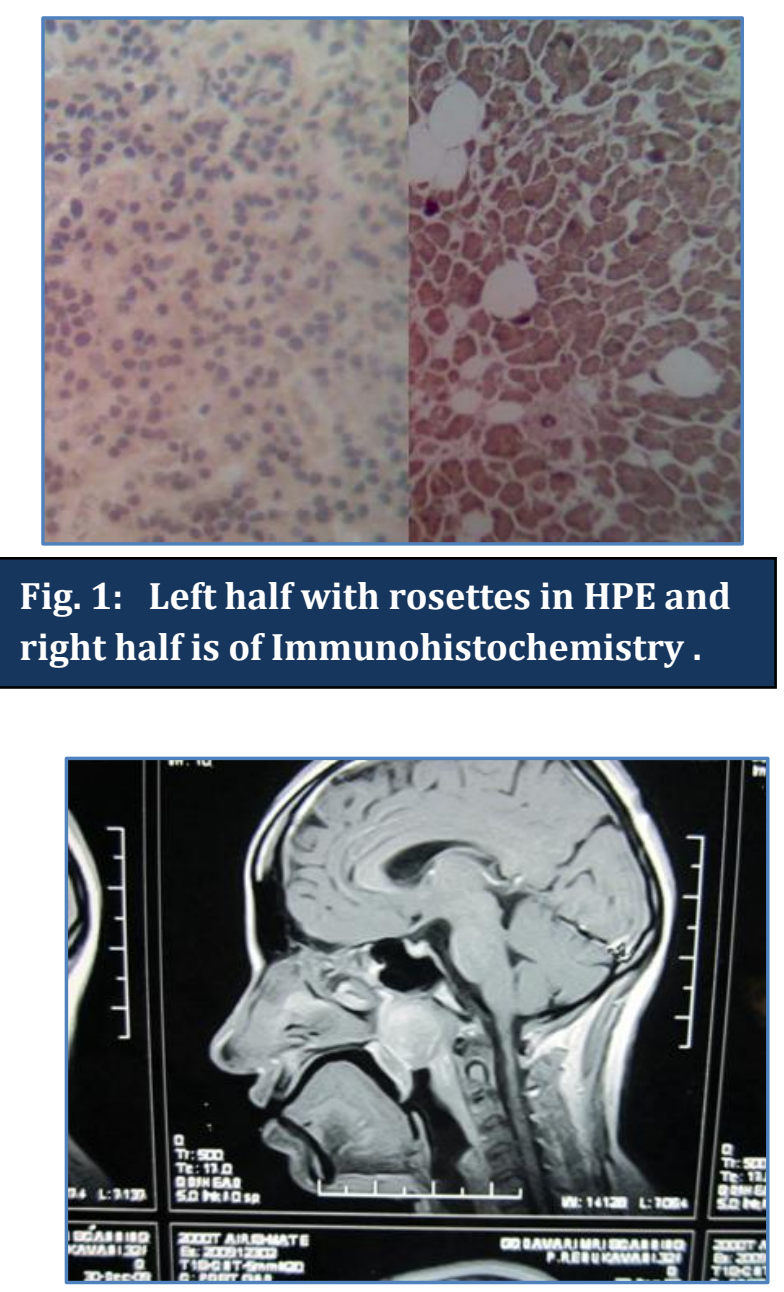

Fig. 2: MRI scan showing mass in Nasopharyx

\section{AUTHORS:}

1. Ravi Kumar Raju Mudunuri

2. Malladi Subramanya Sarma

\section{PARTICULARS OF CONTRIBUTORS:}

1. Associate Professor, Department of ENT, Konaseema Institute of Medical Sciences, Amalapuram.

2. Associate Professor, Department of Pathology, Konaseema Institute of Medical Sciences, Amalapuram.

\section{NAME ADDRESS EMAIL ID OF THE} CORRESPONDING AUTHOR:

Dr. Ravi kumar Raju Mudunuri, Associate Professor, Department of ENT, KIMS, Amalapuram, Andhra Pradesh.

E-mail: drmssharma@gmail.com

Date of Submission: 04/03/2014. Date of Peer Review: 05/03/2014. Date of Acceptance: 20/03/2014. Date of Publishing: 05/05/2014. 